\title{
Estudos
}

\section{Formação de Professores: Racionalidades em Disputa}

\section{Tarso Bonilha Mazzotti}

Universidade Federal do Rio de Janeiro (UFRJ)

Os debates sobre a formação de professores apresentam dois conjuntos de atores sociais que se apóiam em racionalidades antagônicas: um deles é composto por profissionais voltados para a educação de pesquisadores e, o outro, pelos formadores de professores. Ambos apresentam boas razões teleológico, disposicional, posicionai $e$ instrumental para afirmar ou que basta formar o "bom pesquisador" para se ter o "bom professor", ou que a "formação pedagógica" é imprescindível. Um terceiro grupo de interlocutores propõe a síntese entre ambas as posições. Examinando-se essas argumentações e o proposto nas normas para a formação do professor, chega-se a perceber que esta deveria ser centrada no exercício prévio dos atos próprios da profissão. Nesse caso, a formação do professor poderia deslizar para o "tecnicismo" tão justamente criticado. No entanto, esta trajetória não é necessária, pois é possível efetivar o exercício da racionalidade crítica a partir da ação realizada, desde que se esclareça o estatuto da Pedagogia, condição reflexiva da prática educativa.

O debate sobre as licenciaturas ou cursos de formação de professores expressa um antagonismo entre racionalidades diversas que há muito se estabeleceu nas universidades em todo o mundo. 
No final do século passado houve o reconhecimento dos estudos superiores sobre a Educação — Pedagogia —, estabelecendo-se departamentos ou faculdades dedicadas ao tema e à formação de professores e especialistas. No entanto, desde então, ocorre episodicamente a negativa da especificidade desta formação e mesmo do objeto. Parece-me que é no âmbito de tais oposições que se poderá elucidar tanto o debate atual sobre a formação de professores, quanto a especificidade da Educação.

Em linha gerais, há duas racionalidades ou culturas em oposição: 1) a racionalidade dos formadores de especialistas em um campo do saber e 2) a dos formadores ou trabalhadores da educação. Nas seções seguintes examinarei estas racionalidades, apresentando: seus argumentos centrais, a noção de que é possível alcançar uma síntese entre elas e o problema da formação de professores à luz do que foi exposto. Nas seções IV e V sumario alguns aspectos normativos ou legais da formação de professores no Brasil. Finalmente, concluo dizendo que ao se centrar a formação de professores as atividades típicas da profissão corre-se o risco do "tecnicismo", mas esta possibilidade não justifica, de per se, a formação baseada no discurso sobre a escola.

\section{As racionalidades em presença}

Nas universidades verifica-se um debate acirrado entre os docentes que se dedicam exclusivamente às disciplinas acadêmicas típicas de uma área de conhecimento e os que se dedicam à formação de professores. Freqüentemente, para os primeiros, o futuro professor deve, necessariamente, conhecer muitíssimo bem o campo do saber que ensinará, caso contrário estaria ensinando o que não sabe ou pouco conhece. Certamente estes docentes têm toda razão: não se pode ensinar o que se desconhece. Para os que se dedicam às tarefas de formação de professo- 
res, o problema do ensino não se resume em conhecer muito bem a área que se ensinará, fazendo-se necessário o conhecimento das condições sociais e cognitivas dos educandos, a preparação intensiva para o ensino, entre outras. Estes também têm razão, pois não é possível ensinar aos pré-adolescentes e adolescentes sem que se conheça as condições que se apresentam em suas vidas nas escolas e nas salas de aula.

O diálogo entre as duas partes tem se demonstrado impossível por não reconhecerem, cada parte, as boas razões da outra. Freqüentemente os participantes da formação geral e básica na área de conhecimento não reconhecem a legitimidade das preocupações com o ensino para préadolescente e adolescentes, e os da formação direta dos professores não consideram que o conhecimento de uma área deve ser a mais extensa e profunda possível, já que não é neste nível que ensinará aos préadolescentes e adolescentes. Os participantes diretos na formação de professores freqüentemente acusam os demais de julgarem que a educação se reduz à instrução, ao ensino; enquanto os diretamente envolvidos na formação básica consideram que os primeiros são "pedagogistas", ou seja, procuram reduzir o conhecimento ao que será ensinado nas escolas fundamentais e médias.

Encontramo-nos diante de uma antinomia: ambas as partes têm suas razões bem fundamentadas e estas são antagônicas.

As boas razões dos docentes da formação básica apóiam-se nas disposições (conhecimentos) e na posição que têm no campo ou área do saber: o estudante deve conhecer o máximo possível para poder trabalhar com desenvoltura o conhecimento (sentido extenso). Os problemas teóricos e metodológicos de um campo do saber exigem que os estudantes nele obtenham o máximo de desenvolvimento, bem como uma intensiva e extensiva preparação, de maneira a tornar o estudante habilitado a prosseguir por conta própria. Assim considerando, os docentes que trabalham na formação básica aspiram — razão teleológica - a construir o maior número possível de pesquisadores e criadores na área. 
As boas razões dos docentes diretamente envolvidos na formação de professores também são disposicionais e posicionais, mas se apóiam em outros conhecimentos e posições. Os conhecimentos sobre o processo de desenvolvimento cognitivo e afetivo dos estudantes indicam que há necessidade de determinados percursos a serem empreendidos para a efetivação da educação escolar, percursos que tomam os conhecimentos como pretextos para o desenvolvimento da autonomia intelectual dos educandos e não como saberes que estes devam apresentar. Dessa razão disposicional e da posição em que se encontram os formadores diretos de futuros professores, chega-se à formulação de finalidades que são diversas das apresentadas pelos outros. Para os formadores de professores o fundamental é o desenvolvimento dos conhecimentos e atitudes necessários à orientação do processo educativos dos educandos. Centrando a atenção no processo de educação, tem-se que os conhecimentos necessários são, fundamentalmente, aqueles que consideram as limitações do fazer educativo na escola existente, com os estudantes existentes, tendo por pretexto os saberes existentes que são utilizados para a efetivação do melhor desenvolvimento possível do educando. As boas razões teleológicas dos formadores de professores são essencialmente diversas das apresentadas pelos formadores de cientistas, artistas, filósofos etc, já que pretendem realizar a autonomização dos préadolescentes e adolescentes na escolarização fundamental e média.

Para os formadores diretos de professores, a terminalidade da escola fundamental e média impõe-se todo o tempo como a realização do "cidadão", da pessoa capaz de decidir por si os seus papéis na sociedade. Dessa maneira, os conhecimentos (no sentido extenso) são instrumentais para aquela capacitação e não objetivos em si mesmos, isto porque a grande maioria não percorrerá o caminho para a universidade.

Para os formadores dos artistas, filósofos, cientistas, a finalidade do trabalho na universidade só pode ser a realização do campo do saber em que estão envolvidos e, por essa via, construir-se-ia o sujeito do saber e o homem-educado-cidadão-da-elite-bem-pensante, realizável apenas 
pelo ensino superior. A finalidade é formar o especialista bem desenvolvido que se mantenha atualizado em seu campo.

As boas razões apresentadas pelos formadores de professores e as dos envolvidos na formação básica não são conciliáveis por terem sido construídas a partir de situações práticas diversas, com vistas a objetivos diferentes e, até antagônicos.

Considerar que ambos conjuntos de atores sociais possam encontrar uma posição comum através de um curso que combine ambas as formações é supor que se possa superar as duas racionalidades. Pareceme, então, que se labora em ilusão quando se procura combinar formações diversas em um mesmo percurso ou curso.

\section{Seria possível uma síntese entre as duas racionalidades?}

Dizer que é possível alcançar u....; síntese entre os que acentuam a formação profissional do professor e os que desconsideram essa formação, enfatizando a formação nos "conteúdos", significa sustentar que há uma possível formação que compreenda as duas ultrapassando-as.

Como, então, demonstrar essa possibilidade?

Certamente não pode ser por meio de sua simples afirmação. Isto seria circular e não se pode demonstrar a possibilidade através da mera afirmação de uma crença.

O critério para se estabelecer a possibilidade é o da determinação do estatuto epistemológico tanto de um pólo quanto de outro, ou seja, é necessário definir o estatuto do "conhecimento básico" e o do "conhecimento/formação pedagógica", para se verificar a possibilidade de síntese. Exatamente por isso é imprescindível estabelecer se "A" é "A" e quando deixa de ser, tornando-se "A" (não A). Caso "professor" seja 
considerado igual a "pesquisador" ${ }^{1}$, logo idempotentes, as designações deixam de representar "algo" diverso, como é imediatamente reconhecível. Nao é mais necessário, então, pensar ou na "formação do professor" ou na "formação do pesquisador" — ambas se eqüivalem.

Mas aqui o critério não pode ser o do uso das palavras, nem expressar slogans, já que dessa maneira acaba-se por realizar um debate meramente nominalista. O que se exige é uma definição que tenha por critério alguma forma da pragmática ou, no caso, o que faz o profissional (razões instrumental, teleologica, disposicional e posicionai). Não há qualquer outro possível, pois "professor" e "pesquisador" diferenciam-se pelas ações que desenvolvem.

Pode-se dizer que um pesquisador ensina outros pesquisadores, logo é professor. Certamente isso é possível e muitas vezes necessário. Todavia, o pesquisador - no sentido pleno - diferencia-se de outros trabalhadores intelectuais pelas funções predominantes que exerce. Mais ainda, um pesquisador define-se pelo campo de trabalho a que se dedica ativamente. Será que um professor que se envolva ativamente em pesquisas só é professor pelo título, ou seja, formalmente? Novamente estamos caindo na indeterminação retórica. Ser "professor" é exercitar uma função definida, em circunstâncias definidas e apenas nelas. A rigor uma pessoa que exerça a função de professor deixa de sê-lo fora desse contexto; só há, efetivamente, professor e aluno na relação pedagógica. Fora dela são pessoas diferentes: não-professor e

\footnotetext{
${ }^{1}$ As aspas justificam-se. No debate corrente tem-se oposto pesquisador e professor (licenciado) quando, de fato, a oposição deveria ser bacharelando x licenciando, pois é disto que se trata. Nem lodo bacharel virá a ser pesquisador, bem como nem lodo licenciando, pois é disse que se trata. Nem todo bacharel virá a ser pesquisador, bem como nem lodo licenciando tornar-se-á efetivamente professor. O problema maior encontra-se na formação do bacharel em certos campos do saber pois nao há a profissão de bacharel... Mantive a polaridade - formação de pesquisador x de professor — somente para manier a relação posta no debate. Nao significa que concorde com ela nos termos em que estão postos. Afinal o bacharelando nem sempre se realiza, efetivamente, como pesquisador.
} 
não-aluno ${ }^{2}$. O mesmo se pode dizer do pesquisador, caso nao se queira ficar preso a generalidades abstratas.

$\mathrm{O}$ critério para se estabelecer a diferença entre pesquisador e professor não pode ser meramente formal e sim pragmático ${ }^{3}$, nem poderia ser diferente. Pelo critério pragmático, se alcança a efetiva diferença e se supera o discurso meramente formalista.

Voltando à noção de uma síntese possível entre A e A, é preciso lembrar que em lógica isto significa alcançar uma unidade de opostos, onde ambos co-existam. Por exemplo, quando Hegel — em sua Ciência da Lógica - procura examinar o movimento que produziria a unidade de contrários, caminha da afirmação simples, imediata, indeterminada, do Ser (Sein) que nele mesmo põe o não-Ser, o Nada; pois o imediato, o in-delerminado já são negações — o imediato é o sem mediação; o indeterminado, o sem limites (temporais, in- finito; e espaciais, sem bordas). Dessa situação emerge, para a razão, a determinação do Ser pelo Nada, que alcança sua primeira determinação no aqui e no agora, ou seja, no Ser-Aí (Dasein), no Existente (i-mediato). Note-se que a unidade é o reconhecimento da negatividade; só se põe na e pela negatividade, por meio dela se alcança a unidade dos opostos. Por exemplo, a unidade entre a quantidade e a qualidade se põe como medida, ou seja, a medida é a unidade dos opostos quantidade e qualidade.

\footnotetext{
' Tomemos um exemplo fora do ambilo das ciências: Guimarães Rosa, formado cm medicina, fez carreira como embaixador e é reconhecido como um grande escritor da língua portuguesa. Teria sido o curso de medicina que o tornou escritor? Ou será que efetivou as travessias como Riobaldo, que se torna Urutu-Branco no processo mesmo das caminhadas pelo Grande Sertão que é a vida? Riobaldo foi um jagunço na jagunçagem, sendo um contador de histórias quando já aposentado, que conclui dizendo: "Existe c homem humano". As atividades predominantes «põem o que é e vai sendo, nao o formalismo de uma declaração. Tal como o ;'aitato, de Goethe, é preciso reconhecer que "no princípio era a ação"...

' Poder-se-ia dizer "empirismo verdadeiro" de que falava Hegel $\mathrm{cm}$ seu artigo sobre o Direito Natural, do período de Jena. (Cf., por exemplo, Jean Hyppolite, 1946).
} 
Dessa maneira, uma "síntese" opera-se na e pela razão por meio do estabelecimento de um conceito que contenha os opostos, sendo, ele mesmo, um momento de uma relação entre o sujeito e o objeto.

Negar a diferença entre A e A é possível por meio da lógica paraconsistente (Da Costa, 1980), por exemplo, mas só tem sentido nãotrivial caso se possa determinar a situação na qual A e "A são necessários ao entendimento. Certamente é o caso no qual o professor é pesquisador e vice-versa, sendo preciso determinar se e quando tais circunstâncias são imprescindíveis, bem como a natureza do trabalho de professor e de pesquisador. O critério acima expõe a necessidade de se fundamentar a pragmática implícita no que foi dito.

Pode-se considerar que toda ação ou praxis constitui-se de dois aspectos: um, o da efetividade - eficácia e eficiência do fazer que é avaliado pela consecussão do desejado; outro, o anlecipatório ou inferencial — raciocínios que antecipam o que se realizará, logo avaliável com base na qualidade lógica da cadeia inferencial (Piaget, 1987). Uma ação pode ser efetiva sem que sua explicação seja válida, como é comum verificarmos na história das ciências. Por outro lado, podemos nos apoiar em uma "indução correta" que não é validável, do ponto de vista da lógica (Da Costa, 1980). De fato, o racionalismo contemporâneo tem assumido que lógica e razão não se confudem, ao contrário do que pretendem os clássicos (Da Costa denomina-os de "dogmáticos") que postulam a identidade entre razão e lógica (clássica). A razão apóia-se nos seguintes princípios pragmáticos:

1. princípio da sistematização - a razão sempre se expressa por meio de uma lógica; 2. o princípio da unicidade - $\mathrm{cm}$ dado contexlo, a lógica subjacente é única; 3. o princípio da adequação - a lógica subjacente a dado contexto deve ser a que melhor se adapte a ele (Da Costa, 1980, p.45).

Uma explicação, ou seja, um conjunto de induções ou inferências sobre uma prática, pode ser avaliada do ponto de vista da lógica que a 
ele é adequada, mas o critério decisivo será o da experiência. Todavia, a justeza da explicação não se reduz à afirmação da eficácia e/ou da eficiência do fazer. É sempre possível que uma prática eficaz seja explicada de maneira inadequada ou uma explicação de um fazer não apreenda as determinações efetivas. Daí o permanente processo de aproximação do objeto que não podemos supor que algum dia venha a se completar. Disto resulta que a atitude racional só pode ser a da crítica, jamais estagnando-se em uma dogmática. E essa atitude que se deseja efetivar na educação escolar, mas que tem se reduzido a declarações de intenções que assumem ares dogmáticos.

Para encerrar esta digressão, lembro mais uma vez Hegel, que fecha a Ciência Lógica dizendo que o método da lógica, o método absoluto, em si mesmo, é o que reconhece que a "idéia de teoria" e a "idéia da prática" permanecem indefinidamente em contra-dicção. Jamais haveria solução ou término para essa contra-dicção fundamental, sendo ela mesma absoluta, ou seja, indeterminada, logo, infinita: a cada determinação reaparece a in-determinação, que é expressa na "ciência absoluta", no inacabamento da razão.

Finalmente, reconhecer que a formação ou do professor ou a do pesquisador deve fundar-se na pragmática é sustentar que 0 único critério para se estabelecer a diferença é aquele que expressa o que eles que fazem. Mais ainda, a formação tanto do pesquisador quanto do professor jamais se completa na e pela escolarização; ambos necessitam continuar se desenvolvendo nas situações práticas, onde serão ou professor no ensino fundamental e/ou médio ou pesquisador. O que é óbvio, mas freqüentemente se esquece.

Não estou convencido de que se possa alcançar uma síntese entre destinações práticas distintas, mas estou completamente aberto para a argumentação que demonstre a possibilidade. Não estou dizendo que não se poderá fazer por não se ter uma teoria para isto; digo apenas que não vislumbro a teoria que possibilite uma síntese entre práticas diversas. Parece-me que uma solução possível é considerar que o 
professor do ensino fundamental e médio pode ser um pesquisador em Educação, envolvido em investigações sobre o ensino de alguma disciplina, em um programa de formação permanente, mas dificilmente será um pesquisador em uma área do saber não-pedagógico, caso sejam mantidas as condições atuais do trabalho nas escolas.

Isto não significa que considere os professores do ensino fundamental e médio menos capazes do que os pesquisadores universitários ou outros. Na verdade são especialidades diferentes, com atividades diversas, exigências muitas vezes antagônicas, mas uma não será superior à outra em si mesma. $\mathrm{O}$ professor do ensino fundamental que realize com eficácia e eficiência o seu trabalho é tão valioso para a sociedade quanto um pesquisador ${ }^{4}$. Atividades diferentes devem ser avaliadas pelas finalidades ou objetivos a que se propõem e não pelos critérios das demais. Não se espera, por exemplo, que um médico seja um competente pesquisador "de ponta", a não ser que estaja realizando pesquisas de ponta; logo, já não é mais médico em sentido estreito. $\mathrm{O}$ que se espera é que um médico seja capaz de compreender as pesquisas em desenvolvimento e sua aplicabilidade nas situações em que se depara. Por que não exigir o mesmo dos professores que formamos?

\section{Ultrapassando os formalismos indeterminados}

Tomando-se por critério as atividades típicas exercidas pelos profissionais que se deseja formar, alcança-se tanto a definição realista do currículo de formação quanto a superação do antagonismo posto pelas racionalidades antagônicas. A formação do pesquisador em um campo do saber não é e nem pode ser igual à formação do professor para o ensino fundamental e médio, pois trabalharão em situações diferentes e para a realização de objetivos diversos.

${ }^{4}$ Note-se que "pesquisador", aqui, nao se confunde com bacharel, como já anotei ames. 
Aformação de professores para o ensino fundamental e médio exige que o estudante, futuro professor, se dedique integralmente aos estudos e atividades profissionais que irá exercer. Para a efetivação desta diretiva é necessário que o futuro professor se dedique aos estudos necessários a "tradução" dos conceitos de sua especialidade para o ensino fundamental e médio ( $\mathrm{I}^{\mathrm{a}}$ e $2^{\mathrm{a}}$ graus); exercite-se nas tarefas de trabalho coordenado e cooperativo próprios da elaboração de currículo escolares; exercite-se nas atividades de ensino em sala de aula e, por fim, nas tarefas próprias da avaliação do processo educativo tanto de sua disciplina quanto do curriculum escolar. Cada uma destas tarefas exige conhecimentos sobre o educando, as condições da escola, as finalidades e objetivos da educação escolar, bem como o trato com a equipe docente da escola e, certamente, com a matéria de ensino ${ }^{5}$.

A formação de professores, como a de qualquer profissionai, exige que eles se desenvolvam nas atividades cruciais e típicas. Ora, isto só é possível em situações planejads e que envolvam diretamente os futuros profissionais.

Não há como fugir do seguinte: aprende-se a fazer, fazendo. Todavia, tal como estão organizados os cursos de formação de professores no Brasil, aprende-se a fazer falando sobre, ou seja, não se aprendem as tarefas docentes e sim o falar sobre elas. O professor acaba se profissionalizando (ou não) no próprio processo de trabalho que realiza nas escolas quando contratado ${ }^{6}$. Essa situação é, no mínimo, curiosa, pois o melhor da Pedagogia de nossos dias sustenta-se na dire-

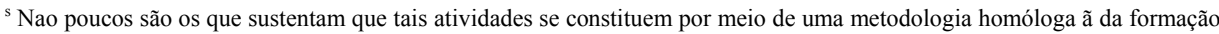
de pesquisadores da Educação, o que parecer ser verdadeiro.

Os profissionais das áreas médicas e paramédicas dedicam bastante tempo à formação profissionai em exercício. Sabem que não se pode ser profissional sem o trabalho efetivo, sendo preciso combinar o trabalho teórico com o prático, tanto nos estágios do curso, quanto em 'residências' para a especialização. Aprende-se a fazer, fazendo, diretiva que a Pedagogia reconhece para a educação em geral e parece desconsiderar na formação de professores.
} 
tiva "aprende-se a fazer, fazendo"7 . No entanto, na formação de professores, tarefa fundamental para a Pedagogia, não se tem dado espaço suficiente para o exercício orientado da profissão. Para se ter as condições mínimas ao exercício prévio da profissão docente é necessário que o futuro professor se dedique integralmente às tarefas docentes.

A principal crítica a este modelo poderia ser a seguinte: ele mantém e aprofunda a separação entre as áreas de conhecimento básico e a formação profissional. No entanto, o modelo oposto - o assumido por muitos - só garante a não separação no papel, pois, como vimos, há duas racionalidades antagônicas e, na prática, a indistinção resulta ou na subordinação da formação dos professores aos cursos de bacharelado, ou na inexistência do bacharelado, por se dar prioridade à formação de professores $^{8}$.

\footnotetext{
${ }^{1}$ Todas as investigações sobre os processos de desenvolvimento cognitivo têm indicado que a construção do pensamento
} tem por base o fazer, sendo que o compreender acompanha, com maior ou menor distância, a efetivação.

\footnotetext{
${ }^{8}$ A formação de professores não se constitui problema apenas brasileiro. Nos Estados Unidos, por exemplo, há um debate nacional que é bastante instrutivo. O National Council for Accreditation of Teacher Education, com base no Schools and Staffing Survey $i^{Q} 87-88$, (National Center for Education Statístics, U.S. Departament of Education) verificou que: $60 \%$ dos professores que ensinam matemática no secundário não possuem cursos correspondentes e nem certificado para o ensino da matemática. Números similares são encontrados para o ensino de ciência e... inglês! Arthur E. Wise, presidente desse Conselho, afirma que 502 escolas estão credenciadas a formar professores; todavia, há inúmeras outras que formam professores; e, mais ainda, há uma proliferação de "programas alternativos de credenciamento" apoiados pelos estados \{Educational Leadership, v.49, n.3, Nov. 1991, p.7). Wise diz que uma crença difundida nos Estados Unidos é que "qualquer pessoa pode ser professor". Sem dúvida, esta mesma crença existe no Brasil. O Prof. John Goodlad, diretor do Center for Educational Renewal, do College of Education da University of Washington, sustenta que uma das razões da falta de preparo dos professores formados pelas universidades encontra-se no caótico sistema de formação que envolve dil fersos departamentos e faculdades, sem que se tenha um programa consistente para produzir o profissionai necessário. Para Goodlad, apenas quando as universidades resolverem formar professores como o fazem para as profissões médica, jurídica, odontológica etc. será possível ultrapassar o estado atual. Ao que Wise retruca dizendo que a profissão docente não é regulamentada ou auto-regulamentada como o são as demais, sendo este um obstáculo importante para a profissionalização, como deseja Goodlad, o que também é verdade para os EEUU mas não para o Brasil, onde o regulamento está na Lei $5.692 / 71$ e normas decorrentes.
} 
A separação entre a formação básica em uma área de conhecimento e a formação do profissional-professor para o ensino fundamental e médio é uma necessidade imperativa. É uma necessidade imperativa tanto do ponto de vista da formação do estudante em uma área ou campo de conhecimento, quanto da perspectiva da formação de professores. A identidade profissional do professor só poderá ganhar com a separação: o exercício nos problemas típicos do trabalho docente produzirá a identidade necessária. Ao mesmo tempo, sendo futuro professor de ..., ele mantém sua identificação com a área ou campo de conhecimento em que se formou. $\mathrm{O}$ fundamental é que não se perca a possibilidade de continuar sua formação básica em cursos de pós-graduação ${ }^{9}$. O que não se pode manter é a atual indeterminação profissional, que contribui muito mais para a degradação do curso de formação de professores do que para o seu desenvolvimento.

Finalmente, e ainda em resposta à crítica mencionada, sustento que a separação das atividades formadoras do médico ou do enfermeiro têm contribuído muito mais para sua identidade profissional e seu desenvolvimento do que a indistinção que seria a sua formação em Biologia, por exemplo. Certamente há, no caso da formação de professores, uma identidade do professor com o que ele ensina, mas sua profissão não é a de biólogo, físico, químico etc. e sim a de professor de biologia, de física, de química, nas escolas do ensino fundamental e médio. Não há dúvidas de que sua formação básica deve ser a melhor possível, mas sua tarefa profissionai, seu trabalho, é fundamentalmente o de professor,

\footnotetext{
${ }^{9}$ A profissionalização do professor apresenta-se como uma exigência cada vez maior para todos os que se dedicam à política educacional. Ernesto Ottoni- (1943, p-12), por exemplo, sustenta ser "necessário pensar em políticas dirigidas à profissionalização e ao desempenho dos educadores, que passem por uma elevação de suas responsabilidades, incentivos, formação permanente e avaliação de seu mérito".
} 
membro de uma equipe docente - ainda que formal ${ }^{10}$ — envolvida no desenvolvimento cognitivo e afetivo dos educandos em idade préadolescente e adolescente. Eventualmente poderá dedicar-se às pesquisas de sua área de formação basica, mas, caso o faça de maneira profissional, deverá ou alcançar uma dupla profissão, ou fazê-lo de maneira amadora. Todavia, ao se planejar a formação de professores, como em qualquer planejamento, é preciso reconhecer as circunstâncias $\boldsymbol{e}$ trabalhar a partir delas. Do contrário corre-se o risco de estabelecer um processo irrealizável, ou de procurar realizar algo que só pode ocorrer como exceção.

\section{Brevíssima história da formação de professores no Brasil}

O debate sumariado acima não é novo no Brasil e nem no exterior. De fato, há uma polêmica internacional sobre a "profissão docente" que percorre todo este século, que viu surgir a educação escolar como um direito do cidadão e uma condição para o desenvolvimento econômico e social. A educação escolar deixou de ser um requisito para algumas classes sociais ou setores de classes para se tornar um "bem" universalizável. Com isto, em nossos dias, a educação escolar não apenas é reivindicada pela população em geral, mas se constitui um setor que envolve dezenas de milhões de alunos e de milhões de professores, em todo o mundo. Tal circunstância produziu a objetivação do trabalho do-

\footnotetext{
${ }^{10}$ A equipe docente é "formar porque o planejamento das atividades escolares é conduzido de maneira a atender a dispositivos burocráticos. De fato, nas escolas, nao se efetiva o trabalho cooperativo (co-operativo) que está suposto no currículo e sim um mero ajuntamento de atividades dos professores, onde cada um julga "sua" disciplina como a mais valiosa para a formação do educando, "esquecendo-se" de que este é escolarizado pelo conjunto dos professores e outros membros da equipe escolar. Nas escolas realiza-se um trabalho semi-artesanal, em que cada professor compreende sua tarefa como separada das demais ou, quando muito, como uma tarefa que pode auxiliar a de outros professores, situação que se reflete na formação de professores em seções separadas, com cada campo do saber tomado por si mesmo, sem relações com os demais que estão envolvidos na fomiação do educando do ensino fundamental e médio.
} 
cente e o desenvolvimento de conhecimentos sobre o processo educativo que têm revisto os procedimentos de ensino-aprendizagem, de organização do trabalho escolar e levando ao permanente reexame dos objetivos e finalidades educacionais. Em nosso país, desde a década de 30, desenvolve-se uma tendência que sustenta a necessidade de se considerar a escola para crianças e adolescentes como um locus facilitador do desenvolvimento do educando, tomando-se por critério os conhecimentos postos pelas ciências, particularmente a Psicologia, a Sociologia e a Antropologia. A educação escolar de massa teria por objetivo a incorporação dos educandos na modernidade, fornecendo os instrumentos cognitivos necessários para a compreensão geral das ciências modernas e do trabalho na sociedade contemporânea. Dessa maneira, a formação de professores deveria centrar-se nas atividades que possibilitem aquele desenvolvimento e não na memorização, por parte do aluno, de fórmulas e palavras.

E neste contexto que se poderá compreender os legisladores brasileiros que formularam tanto a Lei 5.692/71 quanto as Resoluções referentes à formação de professores para o $\mathrm{I}^{\mathrm{o}}$ e $\mathrm{o} 2^{\mathrm{a}}$ graus. Estes legisladores participavam do movimento escolanovista e tinham por critério as diretivas acima indicadas, embora tenham trabalho sob as condições postas pela ditadura militar. O principal formulador da educação de professores foi Valnir Chagas.

Valnir Chagas criticou o "modelo $3+1$ " por se reduzir a presença da Didática ao final da formação do bacharel, dando uma tintura de formação pedagógica ao estudante. Propôs, então, o modelo da formação do professor ao longo da escolarição universitária, sustentando que as disciplinas de formação básica também examinassem de alguma maneira os problemas de seu ensino.

Como se sabe, esse modelo ficou no papel, jamais se realizando como pretendido por aquele ex-conselheiro do Conselho Federal de Educação. 
Revendo-se a crítica de Valnir Chagas e o que se efetiva na formação de professores, pode-se verificar que o modelo criticado permanece em muitas situações e o que foi proposto raramente alcança as dimensões sonhadas.

No acirrado debate entre as duas racionalidades antagônicas - entre os que se dedicam às disciplinas de formação específica e os que se dedicam diretamente à formação de professores — podemos dizer que os vencedores foram os que sustentavam a necessidade do completo conhecimento de uma área para se ser professor, pois esta se tornou a posição predominante nas principais universidades. No entanto, os que sustentavam a necessidade de uma formação centrada nas tarefas típicas do professor, quando tiveram oportunidade de organizar os cursos, pouco demonstraram quanto à efetividade do que propunham. Tudo indica que a crítica do "tecnicismo" resultou na negação peremptória da técnica, substituindo-se a formação profissional do professor pelo discurso ou o falar sobre a educação, cuja efetividade é quase nula. Não é por acaso que algumas pesquisas sobre o ensino tenham eventualmente se desenvolvido fora das faculdades de educação. Nestas predomina o exame das circunstâncias nas quais a educação escolar é possível e não a pesquisa sobre o ensino, por terem incorporado a crítica ao "tecnicismo" de maneria a negar a efetividade da técnica.

Todavia, a proposta de Valnir Chagas fora a de cursos específicos para a formação do professor, profissional exigido pela então nova Lei de Diretrizes e Bases do Ensino (Lei 5.692/71). Sendo o professor um profissional, deveria obter a formação pré-serviço em um curso delineado para tal. Regulamentou-se, então, este curso, estabelecendo-se os mínimos curriculares e as prerrogativas profissionais - por exemplo, os formados em "licenciatura de curta duração" poderiam ensinar no $1^{\mathrm{B}}$ grau, mas não no $2^{a}$ grau. Por outro lado, mantendo uma posição realista, sustentou-se que a forma de articulação dos diversos cursos superiores fosse a mais variada possível: desde cursos exclusivamente profissionais - licenciatura ou formação de professores desde o pri- 
meiro momento de entrada do estudante - até modalidades de aproveitamento de estudos anteriores - por exemplo, o engenheiro agrônomo que desejasse ser professor no ensino de técnicas agrícolas poderia ser licenciado sob certas condições (Esquemas I e II). Para isto o legislador estabeleceu uma condição mínima e especial: os cursos de formação de professores teriam por diretiva curricular ou base de sua racionalidade o que foi denominado de princípio da concomitância, definido da seguinte maneira:

No que toca à formação pedagógica, encontra-se apenas em marcha e, na verdade, evoluindo lentamente, o movimento lançado em 1962 para alcançar maior concomitância do que e do como ensinar. (...) Enquanto isso, a Lei 5.692/71, passou a exigir uma especificidade de habitação, já interpretada na Indicação 22 (item 7.3), em que o conteúdo é função do método e viceversa. Essa interdependência tem de ser buscada muito cedo, na formação regular do licenciado, e reconstruída sempre que ocorra aproveitamento de estudos anteriores. É a Didática entendida como o endereço a imprimir aos conteúdos, acompanhando as diversas fases da escolarização e mesmo confundindo-se com ela enquanto processo (Indicação n" 67, aprovada pelo Plenário do CFF.em 2/ 9/75- grifos do original)

O princípio da concomitancia, que Valnir Chagas traduz dizendo ser a formação pedagógica uma "direção didática dos conteúdos", é assim explicitado:

... a concomitância não [é] um artificial paralelismo de conteúdo e método, mas como (que uma] variação de um em função do outro e de ambos em função dos objetivos a atingir, sempre no aqui e agora do campo configurado. A partir deste ponto, e supondo por certo o domínio de fundamentos e técnicas, o ensinar toma o sentido de arte que também lhe é intrinseco. Exatamente por isto, ele se torna insuscetível de se subordinar inteiramente a receitas nas quais o que esteja separado do como ensinar e neste último - a metodologia - se deixe de levar em conta a quem se ensina, quem ensina e onde, quando, com que c para que o faz (Indicação $\mathrm{n}^{\circ} 68$, depois Parecer $\mathrm{n}^{\circ} 4.873 / 75$, aprovado pelo Plenário do CFE em 4/12/75; grifos do original). 
Pode-se perceber que o conselheiro falava de estudos superiores de educação que, entre outros, habilitariam professores para as partes geral e específica do ensino de $1^{\circ}$ e $2^{\circ}$ graus - licenciaturas -, conforme a Lei 5.692/71". Estes cursos de habilitação de professores não seriam um ajustamento entre o bacharelado e a formação pedagógica e sim cursos destinados exclusivamente à formação de professores. Pode-se ler no Projeto de Resolução sobre Formação Pedagógica das Licenciaturas ${ }^{12}$, no artigo, $\mathrm{I}^{\mathrm{O}}$, o seguinte:

Art. $1^{\circ}$ - Os cursos destinados ao preparo de professores para o ensino de $1^{\circ}$ e $2^{\circ}$ graus compreendem uma parte de conteúdo, estabelecida na Resolução correspondente a cada licenciatura, e outra de fomiação pedagógica, objeto da presente Resolução, ambas devidamente integradas e ajustadas às característica individuais dos alunos em função dos objetivos da Educação Brasileira ao nível escolar considerado.

Trata-se, portanto, de um curso diferente do bacharelado, com currículo próprio, tanto que o artigo seguinte determina:

Art. $2^{\mathrm{a}}$ - A fomiação pedagógica das licenciaturas será concebida e desenvolvida como direção didática dos conteúdos, numa concomitância a ser não apenas consignada nos plano de curso e resepetivas

\footnotetext{
" Ao caracterizar as quatro modalidades básicas em que dividiu os "estudos superiores de educação", a Indicação n" 67/76 (...) encarou a "formação pedagógica das licenciaturas como parte de cada curso, em que se integrará num processo de mútuo ajusta mente com os conteúdos. Previu, ao mesmo tempo, que os mínimos de tal formação seriam disciplinados em pronunciamento único (...) não só por uma espécie de economia normativa [...] como, sobretudo, para garantir a unidade de uma ordem de componentes que só no concreto se diversificará, em função das estruturas identificadas com as diferentes linhas de conhecimento" (Parecer $n^{0}$ 4.873/75).

${ }^{12}$ Mantive o nome "Indicação n* 68/75". No entanto esta se tornou o Parecer no 4.873/75, aprovado pelo Plenário do CFE em 4/12/75; logo, é uma Resolução do CFE.
} 
habilitações, como sobretudo, buscada no preparo final de cada professor diplomado.

\section{(...)}

$\S 2^{\circ}$ - Tendo $\mathrm{cm}$ vista o disposto no artigo $3^{\circ}$, $1^{\circ}$, da Resolução CFE $\mathrm{n}^{\circ} 8 / 71$, que fixou o núcleo comum para os currículos do ensino de $1^{\circ} \mathrm{e}$ $2^{\circ}$ graus, a formação pedagógica deverá fazer-se de modo que o novo professor se torne capaz de, com apoio nos conteúdos tratados didaticamente, cultivar em seus alunos os grandes processos de pensar, sentir c agir que constituem o resultado último de toda a atividade educativa.

O caráter central da concomitancia é o ensino dos conteúdos com vistas ao seu ensino. No entanto, não bastariam os "conteúdos do ponto de vista do seu ensino". Seriam necessárias algumas disciplinas e atividades conjuntamente consideradas como "formação pedagógica" parte do currículo pleno das licenciaturas ${ }^{13}$ — para se efetivar a formação do professor de determinado grau de ensino, de que tratarei mais adiante.

Talvez o engano tenha sido a denominação "concomitância" — pois o entendimento acabou sendo o da "simultaneidade" do ensino de disciplinas ditas de conteúdo com as ditas pedagógicas e não a simultaneidade entre o conteúdo e o método de ensiná-lo. Ora, essa sisimultaneidade só se põe no curso de formação de professores, ou seja, se e quando se tem por objetivo a formação profissional, não se podendo exigi-la quando se organiza um curso com dupla finalidade: bacharelado e licenciatura, por exemplo. Seria o mesmo que desejar formar o biologista e o médico em um mesmo curso: acabar-se-ia não realizando nem um nem outro.

"Feliz ou infelizmente, o CFE apenas expediu Resoluções para alguns cursos, como o de Educação Geral e de Educação Artística, não o fazendo para os demais. Mais tarde, como veremos, com a alteração dos currículos dos ensino de $I^{\mathrm{s}}$ e $2^{\circ}$ graus introduzida pela Lei 7.044/82, a organização dos cursos de formação de professores teria que ser alterada pelo CFE, mas não o foi. 
O relevante é que o "principio da concomitancia" obedece a uma razão instrumental clara: formar professores em cursos especialmente organizados para esta tarefa. Em tais cursos a concomitancia é entendida como uma adaptação do conteúdo e do método de ensino em função dos objetivos a serem alcançados na escolarização ${ }^{14}$.

Como os campos ou áreas de conhecimento são diversos, o desenvolvimento do princípio da concomitância variaria de um setor para outro. Mais ainda, sendo que o professor para o ensino fundamental e médio realiza suas atividades sob determinadas condições, tendo por meio a matéria de ensino, a organização curricular do curso de formação e sua coordenação exigem que se tenha graus variados de concomitância, como assinalava Valnir Chagas.

A proposta de Valnir Chagas sustenta-se em suas boas razões instrumentais: o futuro professor necessita compreender o conteúdo matéria de ensino - e o método de ensinar para realizar com efetivida de - eficácia e eficiência — a sua tarefa. Esta é norteada por objetivos e finalidades que são as de "cultivar em seus alunos os grandes processos de pensar, sentir e agir que constituem o resultado último de toda a atividade educativa". As razões ideológicas seriam, então, o desenvolvimento de um modo de pensar, sentir e agir que se inscrevem na racionalidade moderna ou no racionalismo historicista de que fala $\mathrm{Da}$

\footnotetext{
${ }^{14}$ Atento aos percalços, o ex-conselheiro Valnir Chagas sustentava o seguinte: "0 falo de que a concomitância represente um imperativo doutrinário e prático, agora tomado legal, não lhe assegura presença automática na aprendizagem escolar se deixar de ser cultivada na formação e experiência dos que organizam e promovem o ensino. (...) E evidente que, na busca da concomitância, diversos hão de ser os resultados a obter. Ao menos teoricamente, a formação direta apresenta vantagens sobre o aproveitamento [das experiências de professores que por si mesmo tenham alcançado a concomitância], pois nela c também concomitante a aquisição de conteúdo e metodologia quando consideramos o curso em conjunto. Afinal, corrigir ou completar e sempre mais dificil do que fazer expressamente o certo e o completo. (...) Em vez de considerar a concomitância como uma categoria absoluta e padronizávcl, devemos admitir graus Je concomitância variáveis com os alunos-mestres e com as circunstâncias cm que se desenvolva o seu preparo' ${ }^{11}$ (Parecer CFE $n^{\circ}$ 4.873/75, aprovado em 4/12/75).
} 
Costa (1980). Do ponto de vista da Pedagogia — racionalidade disposicional —, defendido por Valnir Chagas, suas razões são também axiológicas, pois os valores a serem cultivados são os da razão, que se faz ou se constrói historicamente, como se pode depreender dos pronunciamentos do ex-conselheiro nos documentos ao Conselho Federal de Educação.

\section{A profissão de magistério na legislação brasileira}

A doutrina do currículo de formação de professores a ser efetivado no ensino superior - estudos superiores de Educação, na nomenclatura do CFE - tinha, então, por princípio organizativo, a concomitância. A forma de efetivação deste princípio poderia variar segundo os grandes campos do saber que receberam a denominação de "matérias de ensino".

A "matéria de ensino" referia-se aos saberes a serem ensinados nas escolas de $1^{\mathrm{Q}}$ e $2^{\mathrm{Q}}$ graus, ou seja, recortes do saber que teriam certa efetividade na e para a realização das tmalidades e objetivos educacionais estabelecidos em Lei. Dessa maneira, as matérias de ensino seriam umas poucas: Comunicação e Expressão, Ciências e Estudos Sociais (cf. Resolução 853/71 do CFE), em nível nacional, agregando-se-lhes Educação Física e Educação Moral e Cívica. A "matéria" teria o sentido de "matéria-prima" a ser trabalhada no que o legislador denominou de "currículo pleno" das escolas. Oída escola deveria converter as referidas matérias em atividades, áreas de estudos ou disciplinas didaticamente assimiláveis pelos educandos. As matérias de ensino da parte geral do currículo de $1^{\circ}$ e $2^{\circ}$ graus constituir-se-iam a base comum nacional, sendo a parte especial definida regionalmente e/ou para as diversas formações profissionais $\left(2^{\mathrm{U}}\right.$ grau) a serem instaladas.

Para a efetivação da reforma do ensino, o legislador propôs duas medidas quanto aos quadros das escolas: uma, a aprovação do Estatuto do Magistério (Art. 36, da Lei 5.692/71) onde estivesse fixado o regime 
jurídico, de trabalho e remuneração dos professores; outra, estabelecimento de uma formação mínima e suas condições gerais para o exercício do magistério (capítulo V da Lei 5.692/71).

Pela primeira vez, no Brasil, se estabeleciam os contornos da profissão docente para o ensino de $1^{\mathrm{Q}}$ e $2^{a}$ graus, ao se exigir que os sistemas de ensino fixassem um estatuto do magistério, e ao mesmo tempo, a correspondência entre a formação mínima e o nível ou grau de ensino em que os professores poderiam atuar. $\mathrm{O}$ magistério deixava de ser uma profissão de livre exercício, pois a Lei exigia formação mínima ${ }^{\text {is }}$ Dessa maneira, o Conselho Federal de Educação ficou obrigado a estabelecer a doutrina geral e os currículos mínimos das licenciaturas.

Com a alteração da estrutura curricular do ensino de $1^{\circ}$ e $2^{a}$ graus, promovida pela Lei 7.044/82 e pela Resolução CFE 6/86, não se tem mais a organização em grandes campos - matérias de ensino. Reestabeleceu-se o ensino de Português, de Matemática, de História, de Geografia, estabelecendo-se as Ciências Físicas e Biológicas - que incorporaram Programação de Saúde - extinguindo-se a obrigatoriedade da profissionalização no $2^{\circ}$ grau.

Sete anos depois da publicação da Lei 7.044/82, o ministro da Educação editou a Portaria n ${ }^{0} 399$, de 28/6/89, procurando ordenar o caó-

\footnotetext{
^"Lei 5.692/71, Art. 30 —Exigir-se-á como formação mínima para o exercício do magistério:

a) no ensino de $1^{\circ}$ grau, da $1^{\circ}$ a $4^{\circ}$ séries, habilitação específica de $2^{\circ}$ grau;

b) no ensino de $1^{\circ}$ grau, da $1^{\circ}$ a $8^{\circ}$ séries, habilitação específica de grau superior, ao nível de graduação, representada por licenciatura de 1' grau obtida em curso de curta duração;

c) $\mathrm{cm}$ todo o ensino de $1^{\circ}$ e $2^{\circ}$ graus, habilitação específica obtida em curso superior de graduação correspondente à licenciatura plena.

$\S 1^{0}$ - Os professores a que se refere a letra "a" poderão lecionar nas $5^{\mathrm{a}}$ e $6^{\mathrm{a}}$ séries do ensino de $1^{\mathrm{o}}$ grau se a sua

habilitação houver sido obtida $\mathrm{cm}$ quatro séries ou, quando em três, mediante estudos adicionais correspondentes a um ano letivo, que incluirão, quando for o caso, formação pedagógica.

$\S 2^{\circ}$ - Os professores a que se refere a letra "b" poderão alcançar, no exercício do magistério, a 2' grau mediante estudos adicionais correspondentes no mínimo a um ano letivo.

$\S 3^{\circ}$ - Os estudos adicionais referidos nos parágrafos anteriores poderão ser objeto de aproveitamento em cursos ulteriores."
} 
tico registro de professores e especialistas em educação, decorrente das sucessivas alterações legais. Basta examinar a referida Portaria para se ter uma imagem da confusão decorrene das mudanças legais. Alguns exemplos: o licenciado em Filosofia (licenciatura plena) pode ensinar Filosofia, Psicologia e Sociologia no $2^{a}$ grau e História no $1^{o}$ e $2^{\circ}$ graus; mas o licenciado em Ciências Sociais não pode ensinar Filosofia e Psicologia, nem mesmo História nos graus correspondentes aos do licenciado em Filosofia. O licenciado em Química pode ensinar Química e Física no $2^{\circ}$ grau e Matemática no $1^{\circ}$ grau. $\mathrm{O}$ licenciado em Matemática não pode ensinar Química; no entanto, admite-se que possa ensinar Física no $2^{\circ}$ grau. Já o licenciado em Física pode ensinar Matemática nos $1^{\circ}$ e $2^{\circ}$ graus, além de Química no $2^{\circ}$ grau. As situações de registro são tão confusas que o Ministério da Educação está revendo aquela Portaria (Portaria/SESU n ${ }^{\circ}$ 12, de 29/1/93).

A situação atual é a da vigência do modelo de formação de professores fundado na Lei 5.692/71 — Resoluções e Normas do CFE, cuja doutrina de currículo para o $1^{\circ}$ e $2^{\circ}$ graus nada tem em comum com a Lei 7.044/82 e com a Resolução CFE 6/86, produzindo-se, assim, o caos normativo.

Não é de se estranhar que se tenha outra controvérsia: a das prerrogativas profissionais que se entranham nos debates sobre formação de professores. Será que os licenciados e licenciandos em Filosofia admitiriam perder o direito de ensinar Psicologia e História? Os de Física, de ensinar Matemática? Os de História, de ensinar Geografia no 1" grau? E provável que não. Caso o CFE venha a estabelecer a especificidade entre a formação e o âmbito da licença para o exercício profissional, anulando a polivalência vigente, então se instalará uma outra crise nas licenciaturas: a dos estudantes revoltados com a perda de seus direitos...

No entanto, nada mais racional do que sustentar a equivalência entre o que se estudou e o que se pode ensinar. Um professor de Física pode conhecer muito Matemática. No entanto, não realizou seus estudos para 
ensinar Matemática e sim Física. A Matemática necessária para um cidadão que não se especializará em Física certamente é diversa da exigível para aquele que tem esse objetivo.

\section{Concluindo}

Nos parágrafos anteriores, apresentei o quadro geral onde se inscreve o problema da formação de professores em cursos superiores. Procurarei, agora, resumir os argumentos principais:

1. Do ponto de vista das determinações racionais, há duas posições antagônicas no que se refere à formação de professores:

1*) A posição dos docentes que, trabalhando no desenvolvimento de um campo ou área do saber, julgam que o futuro professor não necessita de uma formação diversa da que é fornecida aos demais estudantes da área (bacharéis). Freqüentemente apóiam-se na idéia de que um bom pesquisador $^{16}$ — no sentido amplo — também é ou pode ser um bom professor, seja para que nível for. De maneira mais restrita, sustentam que ninguém pode ensinar o que não sabe, e apenas nisto têm toda razão. A finalidade é efetivar no ensino fundamental e médio a propedêutica aos estudos superiores.

2*) Os docentes que se dedicam à formação de professores sustentam que o conhecimento a ser ensinado é um meio para se desenvolver os educandos, logo, deve ser subordinado às necessidades desse desenvolvimento. Como o desenvolvimento cognitivo e afetivo dos educandos constitui-se chave para que o ensino tenha sucesso, afirmam a necessidade de se conhecer o processo pelo qual o educando vai do estado de

\footnotetext{
" Novamente advirto que os interlocutores têm confundido "bacharel" com "pesquisador", o que nem sempre se efetiva, como se sabe. l'or economia mantive a dualidade proposta pelos interlocutores.
} 
menor para o de maior conhecimento, entendendo que a matéria de ensino é o meio ${ }^{17}$ pelo qual se facilita esse processo. Afirmam, ainda, nue as circunstâncias nas quais se dá a escolarização constituem-se ou obstáculo ou facilitação do processo de educação. Logo, o futuro professor deve conhecer, com acuidade, tais circunstâncias, no que têm toda razão, já que a finalidade é formar os jovens para a vida social, independentemente de que venham ou não cursar o ensino superior.

3') Uma terceira posição sustenta ser desejável e possível uma síntese entre as duas racionalidades anteriormente assinaladas, propondo um curso de formação de professores onde a formação do pesquisador - no sentido amplo — não seja distinta da do professor. Contra ela argumentei dizendo que:

a) a crença na possibilidade de uma síntese não é suficiente para demonstrar a sua efetividade;

b) a demonstração da possibilidade de uma síntese das posições implica a determinação do estatuto epistemológico de cada uma delas, particularmente a definição do campo de saber específico e do campo do saber pedagógico;

c) o critério para a determinação só podendo ser pragmático - no sentido da racionalidade historicista (Da Costa, 1980) - expõe as exigências díspares entre formar o pesquisador e formar o professor;

d) pelo critério pragmático, a atividade de "pesquisador em" e "professor de" são diversas por exigirem habilidades e conhecimentos distintos; dessa maneira não há porque igualá-las.

\footnotetext{
${ }^{17}$ Observe que sustentar que o conhecimento é um "meio", medium, é comum às duas posições. Estas divergem, de fato, quanto ao ponto de chegada: uma deseja efetivar o conhecedor de uma área ou campo do saber; a outra requer o desenvolvimento da pessoa de maneira mais ampla. $O$ antagonismo é muito mais de fins do que sobre a compreensão do papel do saber. Mas, daí, emergem divergências profundas sobre quais saberes devem ser ensinados.
} 
2. A legislação sobre a formação de professores sustenta-se sobre o caráter de profissão do magistério. Deste ponto de vista, o professor é compreendido como um profissional que deve ter uma formação especializada, pois seu exercício não é livre a qualquer pessoa. Esta exigência legal, que reflete a contemporânea compreensão sobre o trabalho docente, estabelece que o curso de licenciatura é similar ao de qualquer outra profissão de nivel superior. Mais ainda, o princípio organizativo dos currículos dos cursos de licenciatura é o da "concomitância", entendida como direção pedagógica ou didática dos conteúdos, ou seja, a não separação (ou o paralelismo) entre o método de ensinar e o saber a ser ensinado.

3. As sucessivas reformas do ensino produziram o caos normativo no que se refere às prerrogativas dos licenciados, situação que só poderá ser ultrapassada por alguma nova norma que estabeleça a equivalência entre o curso realizado e a área de saber em que poderá ensinar. Por exemplo, a atual polivalência do professor de Física que pode ensinar Matemática e Química poderia deixar de ser ratificada, permitindo-se que apenas ensine Física.

O argumento central é o seguinte: o professor é um profissional que se utiliza de um dado saber para conduzir a educação escolar dos educandos do ensino fundamental e médio. Como profissional deve ser submetido a uma formação pré-serviço que centre toda sua atenção nas tarefas típicas da profissão docente.

Essa conclusão banal encontra forte oposição entre os profissionais que sustentam a posição dita "crítica", que julgam ser impróprio formar professores por meio da prática docente pré-serviço. Para eles a tarefa fundamental é a do "desvelamento" das relações sociais que atravessam a vida escolar, sendo o exercício da profissão em situações de préserviço um retorno disfarçado ao "tecnicismo".

Não é preciso muito para retrucar esses críticos. De fato, a efetivação de uma educação do professor por meio e através de atividades 
profissionais em situações de pré-serviço pode conduzir ao predomínio da técnica sobre a reflexão, no que teriam toda razão. No entanto, pelo ¡á conquistado em termos de crítica e avaliação da vida escolar, é possivel organizar um trabalho que coordene a prática docente préserviço com a reflexão sobre o processo escolar.

A reflexão crítica pode ser efetivada sob certas condições como a da determinação do "saber pedagógico" entendido como um conhecimento cujo objeto é a prática educativa, não se confundindo com esta.

Estabelecer o estatuto do saber pedagógico implica considerar a possibilidade de se estabelecer o conhecimento correto e válido da prática educativa, o que supõe a resolução do problema da possibilidade da indução como base do conhecimento. Sabe-se que a epistemologia clássica veda essa possibilidade tanto por sustentar que apenas a lógica clássica tem valor, quanto por se apoiar na posição de Hume sobre a indeterminação dos processos indutivos. No entanto, em nosso século, a lógica clássica foi dialetizada ou relativizada, ao se considerar a existência de outras lógicas bem formadas, e a indução obteve seu lugar na construção do conhecimento científico, sob dadas condições. Dessa maneira, pode-se argumentar que de uma prática é possível se alcançar um conhecimento correto e, em face dos enunciados desse corpus, obter a validação lógica dos enunciados. No caso particular da Pedagogia, condição reflexiva da prática educativa, seria possível - e necessário - desenvolver o trabalho de sua determinação enquanto teoria ou explicação da prática educativa que retenha os enunciados" corretos das diversas posições teóricas, aqueles que seriam validáveis — tanto empírica como logicamente - de maneira a se obter critérios para a avaliação das práticas e de suas explicações (cf. Mazzotti, 1994).

A prática educativa aparece como sendo possível e efetiva para todos. Temos a certeza empírica da efetividade da educação, mas, ao mesmo tempo, temos a dúvida teórica ou duvidamos das explicações apresentadas para o sucesso ou não de determinadas práticas. Essa dúvida constitui-se a base mesma da reflexão, particularmente quando nos 
deparamos com o fracasso do proposto e somos mobilizados a explicar as suas razões. Estas "razões" constituem redes de explicações que são, por sua vez, objeto de exame dos atores envolvidos. Assim, quando se estabelece que a formação do professor deve se centrar no exercício dos atos pedagógicos, instaura-se a prática como educativa por expor os interesses, crenças e condutas dos futuros professores. Crenças, interesses e condutas que precisam ser expostas para serem criticadas à luz de determinadas explicações sobre o fazer educativo. Neste caso, o processo de formação toma a forma de crítica permanente do fazer, alcançando-se o estabelecimento da dúvida teórica que se constitui a característica mais saliente do investigador/pesquisador. Por essa via se alcançaria a síntese entre as racionalidades em oposição? Não sei dizer. Tudo indica que esse processo de dúvida permanente tem um limite bem posto: é preciso realizar o ato educativo, não importa que se tenham dúvidas quanto à melhor maneira de fazê-lo.

Talvez nos encontremos frente a frente aim a "consciência desesperada" que Hegel examinou em sua Fenomenologia do Espírito, mas esse é um outro assunto.

Referências bibliográficas

DA COSTA, Newton CA. Ensaio sobre os fundamentos de lógica. São Paulo: HUCITEC: EDUSP, 1980.

HIPPOLITE, Jean. Genèse et structure de la "Phénomenologie de L'Esprit" de Hegel. Paris: Montaigne, 1946.

MAZZOTTI, Tarso B. Estatuto de cientificidade da Pedagogia. Trabalho apresentado na XVI Reunião Anual da ANPEd, Caxambu, 1994. 
OTTONE, E. Educação e conhecimento: eixo da transformação produtiva com eqüidade; uma visão sintética. Brasília: INEP, 1993. (Série documental. Traduções, 1).

PIAGET, Jean, Vers une logique des significations. Genebra: Mourinonde, 1987.

Recebido em 2 de junho de 1994.

Tarso Bonilha Mazzotti, doutor em Educação pela Universidade de São Paulo (USP), é professor adjunto da Faculdade de Educação da Universidade Federal do Rio de Janeiro (UFRJ).

In the discussion on the preparation of teachers two types of socia actors, supported by opposite rationalities, can be identified, boti presenting good ideological, dispositional, positional and instrumenta reasons: one argues that a "good researcher" will also be a "gooc teacher", while the other sustains that pedagogical formation indispensable. A third group proposes a synthesis between these two positions When analyzing the reasoning presented and the norms that regulate tht preparation of teachers we conclude that this preparation should bi centered on practice of the acts that are inherent to the profession. I, could be argued that this preparation can be turned into "tecnicism". which has been under severe and justified criticism. However, this is no, a necessary trend, since il is possible to exercise the critical rationality of the actions performed, provided that the statute of Pedagogy, reflexive condition of educational practice, is clarified.

À la suite des débats sur la formation des instituteurs, nous venons d'identifier trois sortes d'acteurs sociaux, soutenus par des rationalités 
contraires, l'une 1'autre avec de bonnes raisons d'ordre teleologique, dispositionel, positionel et instrumental; les uns soutienent qu'il suffit former "le bon instituteur", d'autres insiste ni que là formation pédagogique est indispensahle. Un troisième group d'interlocuteurspropose là Synthèse de ces deux oppositions. Lorsqu'on examine ces argumentations et les propositions normatives sur là formation des instituteurs, on conclut que cette formation devrait avoir par but 1'exercice anticipé de Ia pratique des actions qui concernent là profession. Dans ce cas, on pourrait aussi craindre un glissemení de là formation des instituteurs vers le "tecnicisme" aussi sévèrement critique. Mais cetle trajectoire n'est pas nécessaire, car il est possible réaliser 1'exercice de là rationaliié critique en tenanl comme point de départ 1'action réalisée, des que le statut de là Pédagogie soit éclairci en tant que condition réflexive de là pratique éducative.

En los debates acerca de là formación docente puede-se identificar dos tipos de actores Sociales que sustenem racionalidades opuestas, y uno e otro tienen mui buenas razones ideológica, disposicional, posicionai y instrumental: unos afirman que és suficiente formar el "bueno investigador" qui esto será el "bueno docente", otros sustenen que là "formacción pedagógica" és imprescindible. Un tercer grupo de los interlocutores considera posible Ia síntese de Ias dos posiciones. Cuando se examina los argumentos e Io propuesto en Ias normas para là formacción docente, comprende-se qui esta debería estar centrada en Io exercício de los atos peculiares de la profisión. Se poderia ficar temeroso en este caso, que là formación del docente se encaminará al "tecnicismo" que, com Justicia, és criticado. Pero, este camino no és necesario, una vez que és posible efetivar là racionalidad crítica desde Ia acción, una vez que se esclaresca el estatuto de là Pedagogia, condición reflexiva de Ia praxis educativa. 